\title{
HEART BLOCK IN A DIABETIC WITH ONLY MILD ARTERIOSCLEROSIS
}

\author{
BY \\ F. DREYFUSS \\ From the Medical Division of the Rothschild Hadassah University Hospital, Jerusalem \\ Received May 1, 1945
}

Adams-Stokes attacks were observed in an elderly diabetic in whom clinical and anatomical manifestations of arteriosclerosis were minimal. A relation, however, between the underlying cardiac disturbance and the metabolic changes of diabetes was evident. Some rather unusual electrocardiograms were obtained during Adams-Stokes attacks. In view of these uncommon features, and since we have failed to find reports of similar cases, it seemed worth while reporting it in detail.

A dental surgeon, 58 years old, was admitted to hospital with mild collapśe and heart failure on December 24, 1942. His mother suffered from hypertension and one brother from diabetes.

He was born in Palestine, and had had malaria in his youth. He had never been seriously ill until 1929, when he became diabetic. Thereafter he was under the regular care of his physician, Dr. Korkidi, to whom we wish to express our gratitude for his kind co-operation and for the material provided by him. His diabetes proved to be rather severe, but was fairly weil controlled by almost regular insulin injections during the course of many years. Except for a few pyodermic complications (a furuncle of the lip and a phlegmone of the hand in 1936) he had never been obliged to stop work in his dental practice. His blood sugar fluctuated between $167-386 \mathrm{mg}$. per 100 c.c.; his urine was mostly sugar-free and contained only occasionally $0.1-1$ per cent of sugar. Traces of acetone were detected only very rarely. His weight was always normal.

In 1935 he complained of exceptional weakness; his physician noted a slight muffling of the first mitral sound and a blood pressure of $95 / 70$, whereas his blood pressure had always been normal before and remained so afterwards. Later on, no cardiovascular irregularities were observed; examinations of the blood for urea, Wassermann reaction, etc. gave normal results. His pulse rate was usually about 60 . He had never had any anginal pain and hypertension was never noted.

In the middle of 1941, when trying a patent medicine for his diabetes on his own initiative (extract of an Indian mushroom (?) according to his description), and discontinuing his usual dose of insulin, he fainted after a few days and had an attack of convulsions accompanied by unconsciousness. After he had regained consciousness, insulin and stimulants were administered. After a few more attacks he was admitted to the Neurological Department of the hospital (Dr. L. Halpern) in May 1942. A thorough examination, including analyses of the spinal fluid, did not reveal any abnormal findings. The Wassermann reaction in blood and cerebrospinal fluid was negative. His blood sugar at that time was $200 \mathrm{mg}$. per 100 c.c. sugar. A presumptive diagnosis of idiopathic epilepsy was made and treatment was started with impronal (a barbiturate), epanutin, calcium, and parathyroid. Under this treatment a few more attacks occurred.

During the few weeks prior to his admission to the Medical Division, insulin was decreased from 40 to 30 units a day because of a continuous fall in blood sugar. The evening injection on December 23 was given from an ampoule which contained 60 units per c.c. instead of the usual 20 units; as this difference in content was accidentally overlooked the patient got 45 instead of 15 units. Some time later, when feeling that he was " suffering from insulin shock," he took some sweets and glucose. Shortly afterwards a continuous series of convulsive seizures set in accompanied by complete loss of consciousness and of control of the sphincters. During these attacks a very slow pulse was observed by his house physician. Atropine, camphor, glucose intravenously, and ephedrine were subsequently. administered but proved to be of little avail. On the following morning when the attacks finally stopped, his blood sugar was $597 \mathrm{mg}$. per 100 c.c. 
On admission the patient was pale, his extremities were cold, his consciousness was normal, his response somewhat sluggish. He did not complain of any pain or dyspnœa. His pupils reacted to light. The lungs were normal. His heart was in normal limits, the sounds somewhat dull, the pulse urea rate 26-28 a minute, the blood pressure 135/45. The liver was slightly enlarged and tender. Blood urea was $67 \mathrm{mg}$., later $28-42 \mathrm{mg}$., cholesterol $272-151 \mathrm{mg}$., each per 100 c.c. X-ray examination of the heart showed slight diffuse enlargement. Urine analysis revealed only traces of albumin in an occasional specimen. A diagnosis of heart block accompanied by Adams-Stokes seizures was made. Fig. 1 confirmed complete heart block auricular rate 86, ventricular rate 17 . The blood
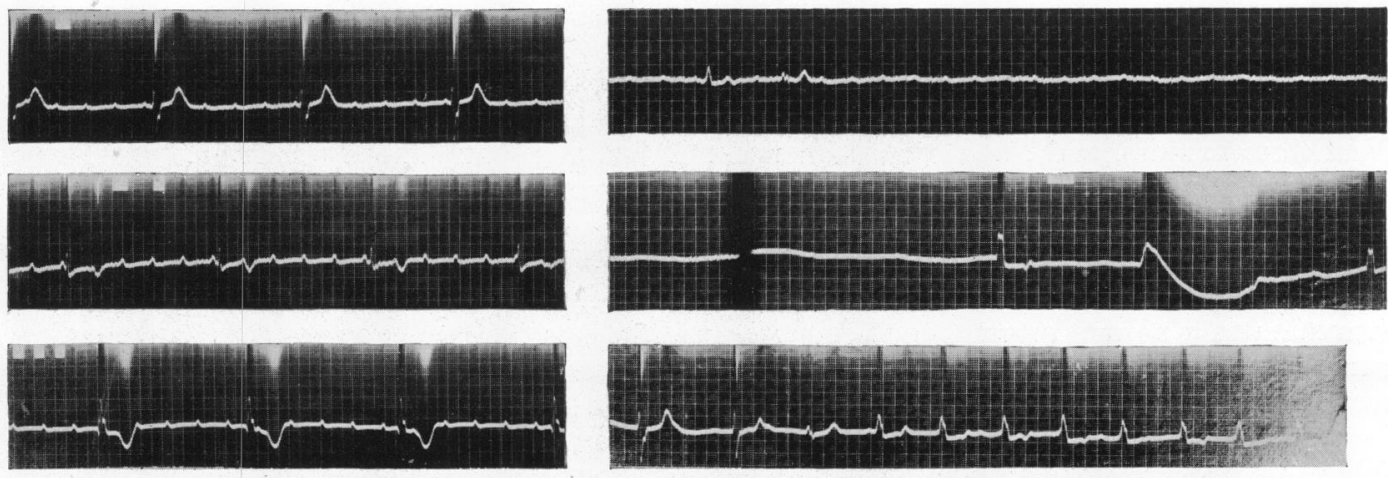

FIG. 1.

FIG. 2.

sugar was $430 \mathrm{mg}$. per 100 c.c. at noon. Altogether 40 units of insulin were given. In the afternoon a new series of attacks began: during one and a quarter hours the patient intermittently fell into unconsciousness preceded by a slowing down of the heart action - the critical rate apparently being 22-until the pulse and heart sounds finally disappeared. One cardiac standstill lasted 55 seconds. It is traced in Fig. 2 showing gradual stoppage of ventricular action, and afterwards of auricular action, reaching a complete standstill both mechanically and graphically. After the zero line the film shows one irregular deflection caused by a violent convulsion. Ventricular action sets in, as a result of different pacemakers (Fig. 3), finally at a rather constant rate of 50, whereas for a certain time no sinus pacemaker and no rhythmic action of the auricles can be made out (Fig. 4).
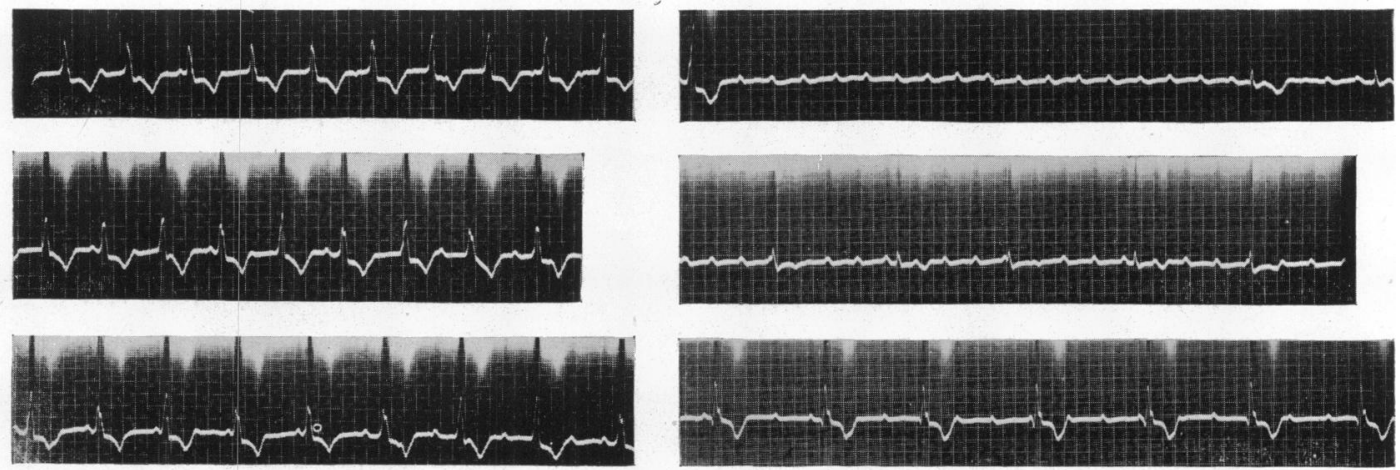

FIG. 3.

FIG. 4.

Another but shorter attack is recorded showing rhythmic $P$ waves, 92 a minute, and subsequently it changes again to complete block (lead II). Respiration usually faded away a short while before the pulse stopped and breathing recurred increasing in its amplitude before the action of the heart could be noticed again. Thus a perfect Cheyne-Stokes periodicity could be observed, somewhat overlapping the Adams-Stokes periodicity of the heart. Several attacks recurred the following night. After 40 units of insulin the morning blood sugar was $136 \mathrm{mg}$. per 100 c.c. On the following day no attacks occurred. On December 26 blood sugar in the morning was $370 \mathrm{mg}$. per 100 c.c.; at noon a series of attacks occurred. It was noted that every time the pulse returned it was quicker, about 36 , and sometimes even nearly 50 for a few seconds; furthermore the blood pressure was 150/60 instead of 140/50 before the Adams-Stokes attack. When, subsequently, the diabetes was kept under control, 
no further attacks occurred for over a month, although the pulse remained slow. Complete block had become re-established.

Up to January 13, 1943, nothing in particular was noted except a continuous improvement of diabetic tolerance. Insulin was correspondingly decreased to 5-10 units in the morning. On January 13, the patient began to run a temperature of $37 \cdot 8-38 \cdot 8$ for three days, due to a small pulmonary infiltration. His pulse rate during the course of this complication was 32-38. His diabetic balance was not affected at all and finally insulin was no longer considered necessary (aglycosuria, blood sugar $176 \mathrm{mg}$. per 100 c.c. on January 28). The patient's diet contained $150 \mathrm{~g}$. carbohydrate, 70 g. fat, 60 g. protein. On February 3, a whole sequence of severe convulsive seizures started without any apparent reason except, possibly, a slight irregularity in his regime. The following morning, the blood sugar rose to $500 \mathrm{mg}$. per 100 c.c., and the patient entered into diabetic coma. 90 units of insulin had to be given, partly intravenously, and the blood sugar was decreased to $310 \mathrm{mg}$. per 100 c.c. A series of severe attacks led to a state of complete asphyxia and cardiac standstill, lasting about three minutes, and death seemed imminent or had apparently already occurred. An intracardiac injection of caffeine and procardin (coramin) was resorted to and the injecting needle, previously motionless, began to show cardiac contractions, in the beginning at a rate of 60 , afterwards decreasing to his usual bradycardia. A short while later, after an injection of insulin, the patient partly recovered consciousness, passing gradually through a state of paraphasia and disorientation to a normal mental condition. As usual, he was completely amnestic as to the entire course of events. On February 8 he had a mild attack, probably as a consequence of an insulin reaction, which was stopped by glucose-an event which occurred several times during this period. A quantity of 25-40 units of insulin applied in three separate injections was necessary to keep the diabetes under a certain, even if unsatisfactory, control-the blood sugar being between $250-300 \mathrm{mg}$. per 100 c.c., glycosuria between 15-50 g. per day, and sometimes even reaching 80 g. Periods of a few days without attacks alternated with a day or two when attacks occurred. The relation between diabetes and cardiac disturbance became more and more blurred, but it must be stressed, as already pointed out, that satisfactory control of the diabetes was no longer obtained. He was transferred to protamin zinc insulin, 20-30 units. For about a fortnight seizures occurred but rarely; regular insulin 10-15 units had to be added. On March 10 a series of violent attacks began, one rapidly following the other and the patient died on March 13,1943, without recovering consciousness. Fig. 5, taken during an atteck, shows transient ventricular standstill interrupted by isolated ventricular impulses, afterwards ventricular trachycardia followed by decreasing auricular action with complete ventricular

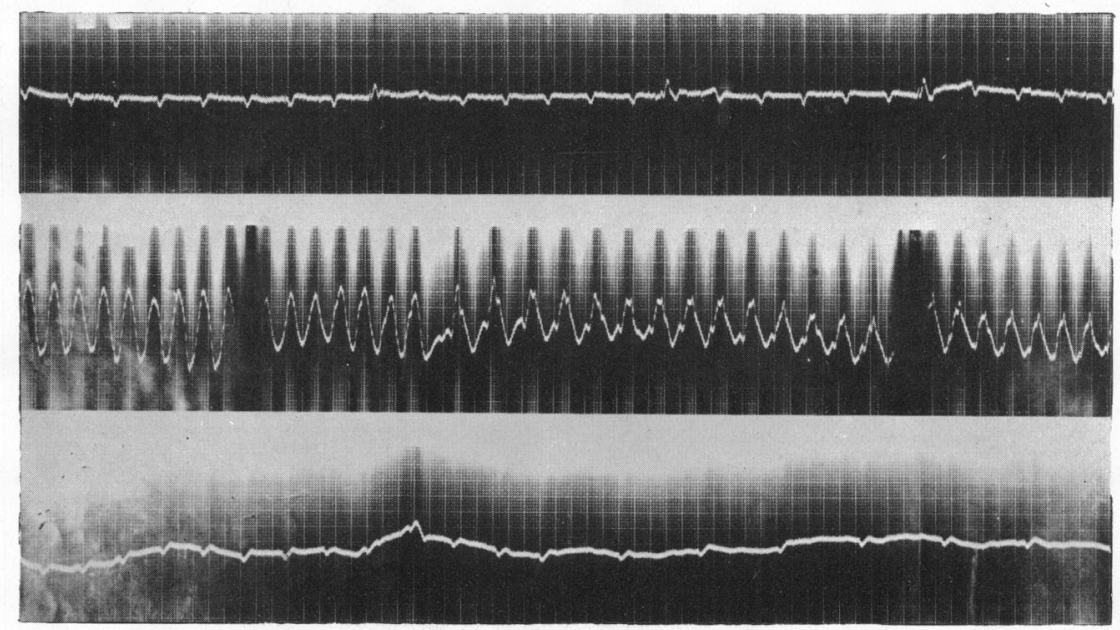

FIG. 5.

standstill. The particular frequency and violence of these attacks may partly be attributed to their occurring during a severe "khamsin" (a hot and dry wind, common in the Eastern Mediterranean), the occurrence of which is often connected with cardiovascular disturbances.

Autopsy (performed by Dr. B. Gellei).

Nervous system: No particular findings.

Cardiovascular system: Heart: slightly enlarged (weight 385 g.) with mild left hypertrophy and dilatation. No gross lesions of the myocardium. Generalized arteriosclerosis of a middle degree 
of the aorta with calcified plaques (near to the arteriae iliacae), and of its main branches; mild arteriosclerosis of the coronary arteries.

Lungs: Bronchopneumonic infiltration in the left lower lobe.

Liver and pancreas: No gross findings.

Kidneys: Of normal size, somewhat firm: surface smooth except for scattered areas which are slightly granular.

Microscopic examination.

Heart: Specimens taken from the right and left ventricles, from the A-V node, the A-V bundle and the origin of its two branches, as well as from the lower part of the interventricular septum, showed no pathological changes. Serial sections taken from the A-V system showed no pathological findings. In the right lower portion of the fibrous septum there were several foci of calcification without connection with the right bundle branch. The myocardium is normal. The arteries show very mild arteriosclerosis. Glycogen stain taken from a section of the anterior wall of the left ventricle: glycogen positive, small droplets of glucogen, larger droplets in the part near the myocardium.

Liver: Chronic passive congestion. Plenty of glycogen in the nuclei of parenchyma cells.

Pancreas : No pathological changes.

Kidneys: Apart from mild arteriosclerosis of the large and middle arteries, no changes.

Adrenal glands: Slight hyperplasia of the cortex, at some areas of nodular type.

Lungs: Beginning bronchopneumonia in block taken from the left lower lobe.

\section{Discussion}

It is rather significant that the epileptiform seizures, as described by the patient's family, were interpreted as epileptic fits which made their appearance unusually late in life. Cerebral symptoms are not infrequently an initial and outstanding feature in heart disease. Only close observation revealed the true cause of the attacks: the paroxysmal cerebral ischæmia (Fishberg, 1940) being caused by a severe disturbance of cardiac rhythm on the basis of changing degrees of heart block. This block seems to have passed through several stages; it had apparently been of an intermittent nature, in itself a rare occurrence (Comeau, 1937), in a period before, as well as after, the patient's first stay in hospital-his pulse was 60 in the intervals between attacks; A-V block became "complete" and " established ", as Campbell (1944) puts it, at any rate after the patient's second admission to hospital. Typical AdamsStokes attacks were observed when his ventricles came to a complete standstill, that is to say, when even the ventricular pacemaker stopped its action or its impulse was prevented from spreading over the ventricles ("block in block" (Schmoll)). The sudden onset of ventricular standstill in a pre-existing complete A-V block is an occurrence that requires explanation. The same theories that have been adopted for intermittent interruptions of $\mathrm{A}-\mathrm{V}$ conduction apply - besides the changes of vagal inhibition-in these cases also. Some subtle local circulatory deficiency as suggested by Carter and McEachern (1934), may prevent the spreading of impulse over the ventricle. Dubbs (1938) rightly sums up the general state of knowledge by confessing our ignorance of the immediate cause of ventricular asystole that leads to the Adams-Stokes syndrome. In one instance at least, even auricular inactivity was demonstrated by a cardiogram that failed to exhibit any impulse (sinus?) whatsoever, thus surpassing in its negativity as an in vivo finding tracings which have been taken even a considerable time after clinical death. In the patient's last days attacks were observed occurring on the basis of ventricular fibrillation which represents another cardiac condition leading to cerebral ischemia.

The explanation for the occurrence of the cardaic disturbance was usually to be found in the fluctuations of diabetic balance. This relation is borne out, for example, by Fig. 6 showing the incidence of attacks and diabetic balance at the beginning of the patient's stay in hospital. The onset of these paroxysms was usually observed when any irregularity in the treatment of his diabetes occurred (overdose of insulin, hyperglycemia). On the other hand, even a short series of attacks tended to derange completely his metabolism to the hyperglycæmic side, thus provoking a rise to more than $500 \mathrm{mg}$. per 100 c.c. after an attack which had been caused by an overdose of insulin.

It seemed rather natural to assume that arteriosclerosis, especially of the coronary and cerebral vessels, was the underlying anatomical condition of a man, 58 years old, who had 


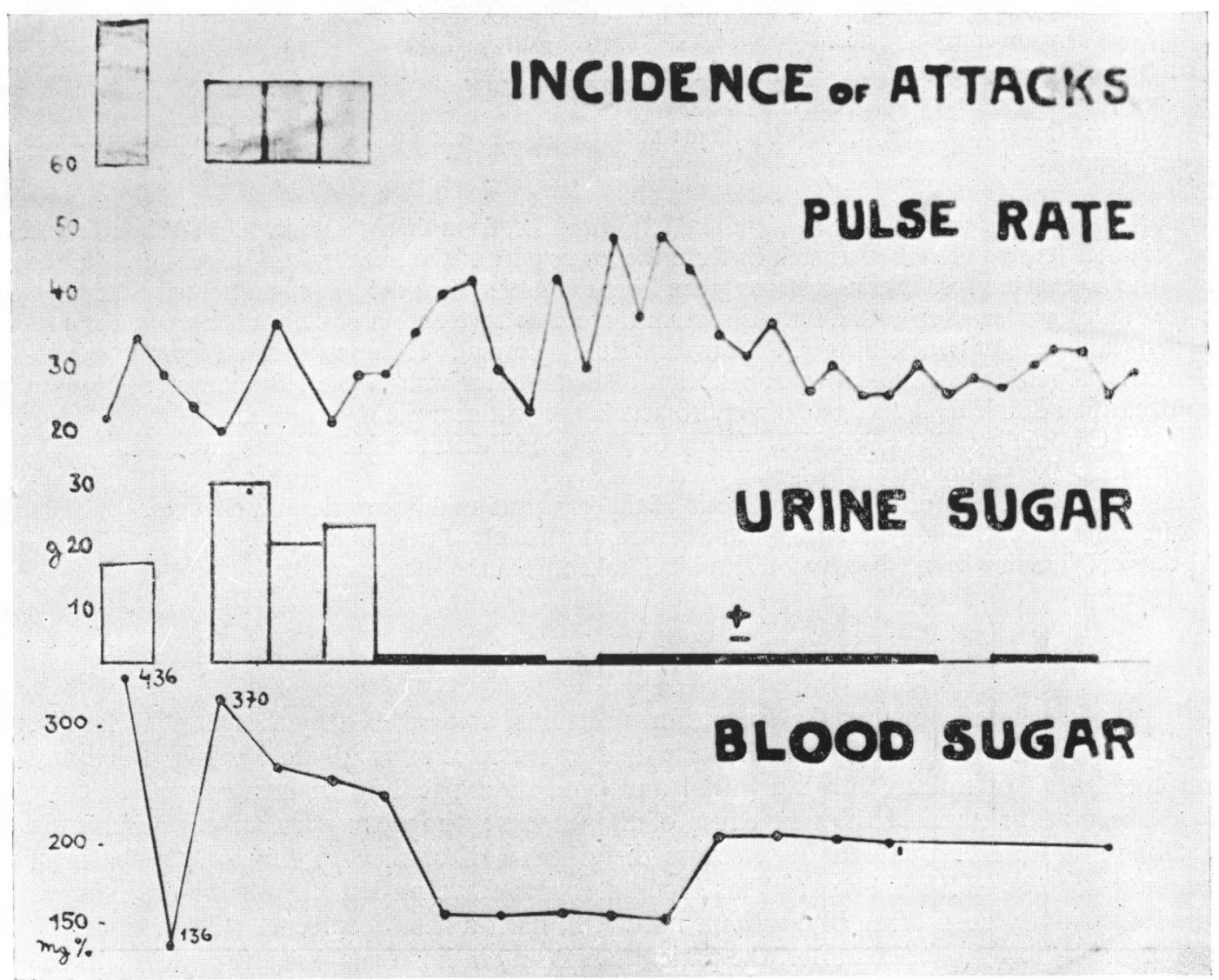

FIG. 6.

been suffering from diabetes for 13 years. Under the circumstances it may be understood that a coronary occlusion was taken into consideration as the possible source of that severe series of attacks provoked by an overdose of insulin the night before his admission to hospital. To our great surprise the findings at autopsy were those of mild arteriosclerosis, in the words of the pathologist, " not even corresponding to the patient's age and by no means explaining. the severe disturbances described." In this respect our case bears some resemblance to that of Lawrence and Forbes (1944) suffering from paroxysmal heart block and ventricular standstill, in which post-mortem examination also showed " no gross abnormality of the heart " and the atheromatous changes in the coronary arteries "were not sufficient to obstruct the lumen at any point". Retrospectively, the absence of the psychic behaviour characteristic: of cerebral sclerosis, the absence of retinal signs of this disease, and the lack of anginal pain, should be stressed.

An explanation other than the various changes in the structure and tone of arteriosclerotic vessels must therefore be sought. Taking into consideration the close interrelationship existing. between the state of diabetes and the behaviour of the heart, a causal connection between cardiac and metabolic disturbance seems most probable. Under the weight of the overwhelming evidence of arteriosclerosis in diabetics, other mechanisms apt to bring forth such disturbances have been only rarely discussed. A case of transient heart block in a diabetic woman, 56 years old, was reported by Blaisdell (1935). In this case, however, partial A-V block occurred for a short period following coronary thrombosis. Joslin (1940), who lays stress on the " astonishing " frequency of arteriosclerosis as a post-mortem finding in diabetics, mentions also degenerative changes in the myocardium not dependent on coronary diseases as having been noted by a number of writers. Nathanson (1932) describes the finding of a pale, swollen, cloudy heart muscle in most cases of diabetic acidosis_and_coma. In our case, 
who only rarely reached the state of intensive acidosis and for short periods only, a metabolic influence upon the cardio-cerebral regulation, according to the clinical observation primarily on the cardiac regulation, may be suggested in the light of the cases described by Shirley Smith (1943). He assumes " that diabetes exerts a deleterious effect on the myocardium, not only by virtue of coronary sclerosis, but also through direct impairment of the parenchyma of the heart ". The maintenance of a sufficient carbohydrate combustion is, in his opinion, at least as important, if not more so, than the provision of an adequate oxygen supply to the myocardium. Deficient carbohydrate utilization is the only feature common to hyper-and hypo-glycæmia and may so, to a certain extent, explain similar cardiographic patterns (especially of the S-T) observed in both conditions and in the same way the observations made in our patient. The nutritional state of the myocardium in this case may be seriously affected by abnormal composition of the blood feeding it, whereupon its irritability and conductivity may be thrown out of order. This may be true particularly of the A-V conduction system, the metabolism of which is probably more sensitive to these alterations on account of the more embryonic nature of its muscle fibres. Harrison and Finks (1943) analogously point out that "fuel deficiency will tend to produce in the tissues metabolic disturbances similar to those induced by oxygen deficiency". On the other hand, the fact that the patient could be tided over some lighter attacks simply by diverting his attention may point to a cerebral part in this complicated mechanism, the brain in itself being similarly subject to the disturbances of tissue nutrition produced by metabolic fluctuations. This mechanism finally became completely upset, the correlation between diabetes and cardiac disturbance becoming lost; in this last period, however, satisfactory control of diabetes was no longer obtained; cardiac, metabolic, and cerebral regulations became progressively destroyed.

In accordance with these considerations success and failure as to the appearance of attacks were largely determined by the control of diabetes at the corresponding moment. In this respect therapy was successful for a certain time. As a matter of fact, only insulin and glucose respectively were effective in controlling the seizures. Apart from these two substances a good many drugs were given a trial. Since severe arteriosclerosis, as explained above, was assumed to be the underlying condition, doses of several of them were applied rather cautiously; adrenaline and barium chloride were therefore completely excluded. Atropine, ephedrine, erythrol-tetranitrate, and potassium iodide, were of no avail. Aminophylline sometimes seemed to shorten a series of attacks when given into the vein, and definitely influenced only Cheyne-Stokes respiration. Caffeine was successfully used for resuscitation when injected intracardially; it occasionally seemed to shorten an attack. Oxygen did not abolish the attacks but had, at least for a few weeks, a considerable and interesting effect: during its administration no epileptic convulsions appeared and consciousness was usually not lost completely; the pulse did not entirely disappear, but the periodicity of respiration and cardiac disturbance remained uninfluenced. When oxygen administration was stopped, a violent seizure followed almost immediately. This partially modifying action of oxygen has been observed in a similar way by Miller and Fulton (1941). Digitalis had no effect upon the disturbance of rhythm or on the liability to attacks.

A good deal has been written about the relationship of Cheyne-Stokes respiration to Adams-Stokes attacks. Various different patterns of behaviour have been observed and there is no consensus of opinion regarding the frequency of these conditions together: whereas Wenckebach and Winterberg (1927) or Steele and Anthony (1933) remark on the rarity of this coincidence, Price (1927), for example, considers it as a fairly common combination. In the case of Hamburger,'Katz, and Rubinfeld (1931-2) " the change in block synchronized with the change in the character of breathing". A similar occurrence was the one observed in our case.

The case described represents a rare cardio-cerebral complication in a diabetic, the severity of which is illustrated by the violence of the seizures and by the lethal outcome. It belongs to a category of heart disease which, comprising also, among others, heart disease caused by vitamin deficiency, might be designated as " nutritional heart disease"; a classification that points to the nutrition of the heart muscle being at fault-in our case owing to a disturbance of carbohydrate metabolism. 
A case is reported of complete A-V block in an elderly diabetic in whom post-mortem examination revealed only mild arteriosclerotic changes, especially of the coronary circulation. Many series of Adams-Stokes attacks were observed, accompanied by Cheyne-Stokes respiration. These seizures were mostly caused by ventricular standstill and finally also by ventricular fibrillation. These mechanisms are demonstrated by electrocardiograms; in one instance even auricular stoppage was graphically demonstrated.

As the anatomical findings by no means explain the profound disturbances of cardiac action, and as, on the other hand, it was noted that these attacks usually occurred when diabetic balance was seriously upset, an attempt is made to explain the changes in cardiac behaviour by metabolic fluctuations. It is suggested that these fluctuations interfere temporarily with the normal nutrition of the heart muscle, possibly foremost of the A-V conduction system, whenever hypoglycæmia or hyperglycemia prevails.

The applied treatment is briefly discussed.

\section{REFERENCES}

Blaisdell, E. R. (1935). J. Amer. med. Ass., 105, 1518.

Campbell, M. (1944). Brit. Heart J., 6, 69.

Carter, E. P., and McEachern, D. (1931). Bull. John Hopkins Hosp., 49, 337.

Comeau, W. J. (1937). Amer. J. med. Sc., 194, 43.

Dubbs, A. W. (1938). Amer. Heart J., 16, 235.

Fishberg, A. M. (1940). Heart Failure. London, p. 278.

Harrison, T. R., and Finks, R. M. (1943). Amer. Heart J., 26, 147.

Hamburger, W. W., Katz, L. N., Rubinfeld, S. H. (1931-32). Ibid., 7, 498.

Joslin, E. P., Root, H. F., White, P., Marble, A. (1940). The Treatment of Diabetes Mellitus, London. Henry Kimpton. p. 437.

Kulbs, F. (1928). Handbuch der Inneren Medizin, Berlin. Vol. II, part 1, p. 98.

Lawrence, J. S., and Forbes, G. W. (1944). Brit. Heart J., 6, 53.

Miller, H., and Fulton, F. J. (1941). Ann. intern. Med., 14, 2296.

Nathansen, M. H. (1932). Amer. J. med. Sci., 183, 495.

Price, F. W. (1927). Diseases of the Heart. Oxford University Press, p. 208.

Schmoll (quoted from Wenckebach and Winterberg).

Smith, S. and Hickling, R. A. (1933). Lancet I, 632.

Smith, K. S. (1943). Brit. Heart J., 5, 1.

Steele, J. M., and Anthony, A. J. (1933). Amer. Heart J., 8, 357.

Wenckebach, K. F. and Winterberg, H. (1927). Die Unregelmässige Herztätigkeit, Leipzig, p. 389ff. 